\title{
Numerical Simulation of Solidification Structure Formation for a Large Flat Ingot during Water-cooled Mold Casting
}

\author{
Huishu Zhang ${ }^{1, a^{*}}$, Lina Sun ${ }^{1, b}$ and Dongping Zhan ${ }^{2, c}$ \\ ${ }^{1}$ School of Metallurgy, Liaoning Institute of Science and Technology, Benxi, 117004, China \\ ${ }^{2}$ School of Materials \& Metallurgy, Northeastern University, Shenyang 110004, China \\ ahuishuzhang@163.com, ${ }^{b}$ linasunwu@163.com, czhandp1906@163.com
}

Keywords: Casting, ingot, numerical simulation, water-cooled mold, solidification structure

Abstract. There are some new water-cooled ingot caster were built in some steel plant in China for produce large flat ingot to meet the increasing requirement of the large ingot. While as the ingots become larger, there may cause many metallurgical imperfections, such as segregation, surface defects, etc. For predicting and investigating the quality of the large flat ingot casted by a new built water-cooled ingot caster, a numerical model is established to predict the solidification structure formation. Then the predictions are validated by comparing against metallographically measured results. The results show that the temperature decreases very quickly and keep the similar curves for different nodes on the surface of the cast. With the increase of pouring temperature, the columnar grain area is bigger. When pouring temperature is $1530{ }^{\circ} \mathrm{C}$, ingot solidification organization mainly composed of fine crystal area and a wide range of internal equiaxed grains zone. The porosity is mainly formed in the top part of the ingot. The depth of the shrinkage porosity will deduce $31 \mathrm{~mm}$ when the casting temperature decreases to $1530^{\circ} \mathrm{C}$ from $1550^{\circ} \mathrm{C}$.

\section{Introduction}

With the increasing of ingot size, the quality problem is increasingly highlighted. Such as the segregation, porosity, surface defects, etc [1]. Numerical simulation of solidification is useful in getting high quality castings and minimising product cost and scrap and it has been used in ingot casting for many years $[2,3]$. The microstructure control in large steel ingots is one of the most well-known and now classical problems in the field of solidification and casting[4]. J P GU got that the variation of the final solidification temperature due to macrosegregation is important for a large steel ingot $[5,6]$. Z H Zhang built a three dimensional incompressible gas-liquid two-phase flow model to simulate the fluid flow of casting's mould filling process [7]. K Marx performed an systematic investigations concerning the filling process phenomena by application of advanced physical and numerical simulation methods [8]. Z H Duan investigated the formation of macrosegregation in a large steel ingot by analyzing the whole filling and solidification processes [9]. J Guo developed a dimensionless Niyama model to predict local microporosity by accounting for local thermal conditions during casting as well as the properties and solidification characteristics of the cast alloy[10].

In this paper, a numerical model is established to predict the solidification structure in a large flat ingot within a new built water-cooled mold caster. The predictions are validated by comparing against metallographically measured results.

\section{Experimental Principle}

Mathematical Model. The model is based on the numerical solutions of the Navier-Stokes and Fourier equations.

Mathematical Modeling of Fluid Flow. Incompressible Newtonian viscous fluids are assumed. The mass conservation is shown as following.

$\operatorname{div} \mathrm{V}=0$.

And the N-S equations: 


$$
\begin{aligned}
& \rho\left(\frac{\partial u}{\partial t}+u \frac{\partial u}{\partial x}+v \frac{\partial u}{\partial y}+w \frac{\partial u}{\partial z}\right)=-\frac{\partial p}{\partial x}+\rho g_{x}+\mu \nabla^{2} u . \\
& \rho\left(\frac{\partial v}{\partial t}+u \frac{\partial v}{\partial x}+v \frac{\partial v}{\partial y}+w \frac{\partial v}{\partial z}\right)=-\frac{\partial p}{\partial y}+\rho g_{y}+\mu \nabla^{2} v . \\
& \rho\left(\frac{\partial w}{\partial t}+u \frac{\partial w}{\partial x}+v \frac{\partial w}{\partial y}+w \frac{\partial w}{\partial z}\right)=-\frac{\partial p}{\partial z}+\rho g_{z}+\mu \nabla^{2} w .
\end{aligned}
$$

Where $P$ is the density of the fluid, $\mu$ the viscosity, $g$ the gravitational acceleration, $\mathrm{u}, \mathrm{v}, \mathrm{w}$ is the velocity of $\mathrm{X}, \mathrm{Y}, \mathrm{Z}$ directions, and $\nabla^{2}$ is Laplace.

$$
\nabla^{2}=\frac{g^{2}}{g x^{2}}+\frac{g^{2}}{d y^{2}}+\frac{g^{2}}{a z^{2}}
$$

Mathematical Modeling of Heat Transfer. Fourier equation was used to calculate the heat transport.

$$
p c \frac{\partial T}{\partial t}+p c u \frac{\partial T}{\partial x}+p c v \frac{\partial T}{\partial y}+p c w \frac{\partial T}{\partial z}=\frac{\partial}{\partial x}\left(k \frac{\partial T}{\partial x}\right)+\frac{\partial}{\partial y}\left(k \frac{\partial T}{\partial y}\right)+\frac{\partial}{\partial z}\left(k \frac{\partial T}{\partial z}\right)+S
$$

Where $\mathrm{u}, \mathrm{v}, \mathrm{w}$ is the transport velocity of $\mathrm{X}, \mathrm{Y}, \mathrm{Z}$ direction, $\rho$ the density, $\mathrm{c}$ the specific heat, $\mathrm{k}$ the conductance coefficient and $\mathrm{T}$ the temperature. $\mathrm{S}$ the inner heat source, here is the latent heat between liquid-phase and the solid-phase.

$$
S=\rho \mathrm{L} \frac{\partial f_{x}}{\partial_{\mathrm{t}}} \text {. }
$$

Geometry and FE model. The geometry dimensions of the model are as follows: $500 \mathrm{~mm}$ (Width) $\times 2300 \mathrm{~mm}$ (Height) $\times 2000 \mathrm{~mm}$ (Length). The mesh for the simulation is shown Fig. 1 (a). And for showing the different temperatures in the cast, some nodes locations are shown in Fig. 1 (b). They are named as $72282,27271,50584,72102$ and 2718 from the top to the bottom on the left narrow side wall. On the right side wall, they are 41720, 55481, 11631, 41638 and 61062. They are 50584, 22432, 54332 and 24444 from left to right on the center line.

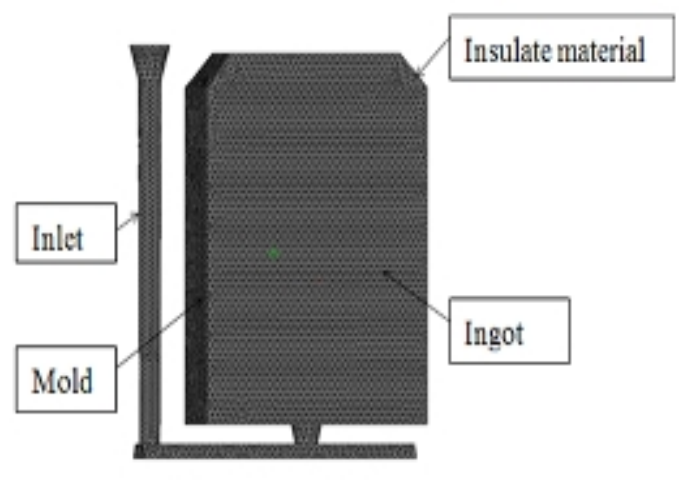

(a)

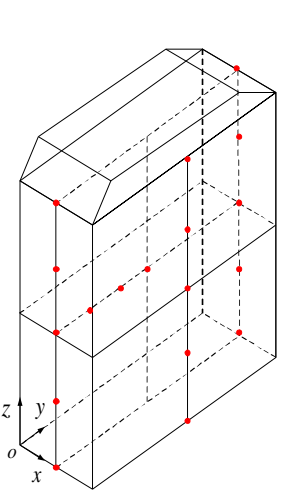

(b)

Fig. 1 Mold used for simulation

Boundary Conditions and Loading. Some reasonable assumptions were made as following: Set zero displacement on the $\mathrm{X}, \mathrm{Y}$ and $\mathrm{Z}$ directions for three corner nodes of the mold. The physical parameters of the steel are depend on the variation of the temperature, and some unknown variables are considered constant. The temperature and the velocity of molten steel are constant and stable during casting time. The air in the mold is ignored while calculating the filling and solidification process of the ingot.

The following conditions are applied to the models. Conductance coefficient between Ingot and mold is $2000 \mathrm{~W} / \mathrm{m}^{2} \cdot \mathrm{K}$. Conductance coefficient of air is $10 \mathrm{~W} / \mathrm{m}^{2} \cdot \mathrm{K}$. Conductance coefficient of water is $10000 \mathrm{~W} / \mathrm{m}^{2} \cdot \mathrm{K}$. Inlet velocity is $0.5 \mathrm{~m} / \mathrm{s}$. Initial temperature of the mold is $25^{\circ} \mathrm{C}$.

Experimental Validation. In order to provide initial validation of the above developed model, several casting results from a steel plant were investment cast. Some of the test samples were cut into halves for more detailed metallography and to confirm the porosity levels. 


\section{Results and Discussions}

Temperature Versus the Time. The variations of the temperature on the node are shown in Fig. 2. The temperature decrease very quickly and keep the similar curves for different nodes on the surface of the cast. But for that of the node 72282, for its location is on the corner of the mold, the curve of the temperature has a short time increasing between $1000 \mathrm{~s}$ and $2000 \mathrm{~s}$. After casting more than $3000 \mathrm{~s}$, the temperature of the center line nodes decrease gradually.

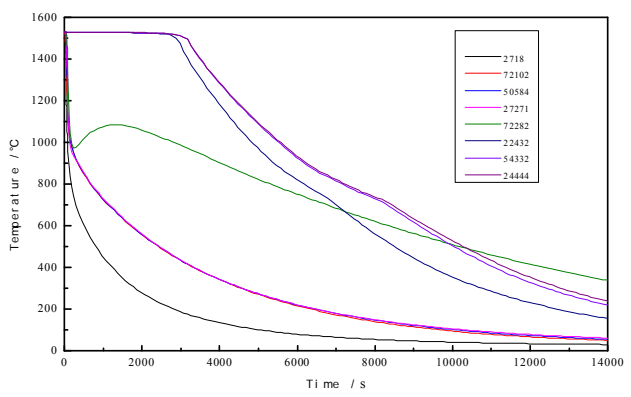

Fig. 2 The node temperature varied versus time

Solidification Structure. Fig. 3 shows the graphics of the primary dendrite arm spacing at different casting temperature. It can be seen that, with the increase of pouring temperature, the columnar grain area is bigger. when pouring temperature is $1530{ }^{\circ} \mathrm{C}$, ingot solidification organization mainly composed of fine crystal surface area and a wide range of internal equiaxed grains zone. When pouring temperature is $1550{ }^{\circ} \mathrm{C}$, the columnar crystal has been quite developed and some of left or right columnar crystal cross the center line. Thus, in order to obtain good microstructure of the ingot, it is better to cast at low over temperature. Fig. 4 shows the microstructure of a water-cooled ingot. Its' solidification structure is very similar as the simulation results.
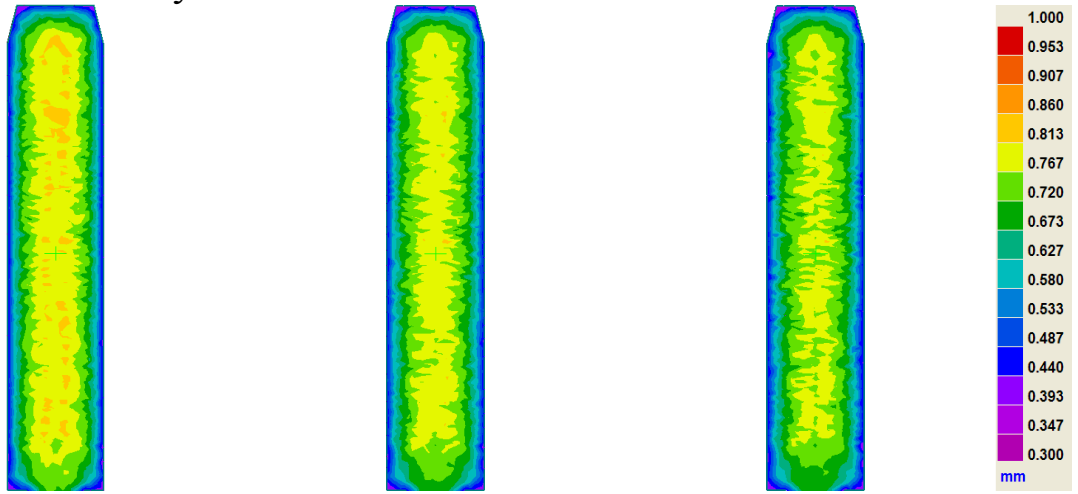

(a) Casting at $1530^{\circ} \mathrm{C}$ (b) Casting at $1540^{\circ} \mathrm{C}$ (c) Casting at $1550^{\circ} \mathrm{C}$

Fig. 3 Primary dendrite arm spacing ( $\mathrm{x}=250 \mathrm{~mm}$ crosssection)

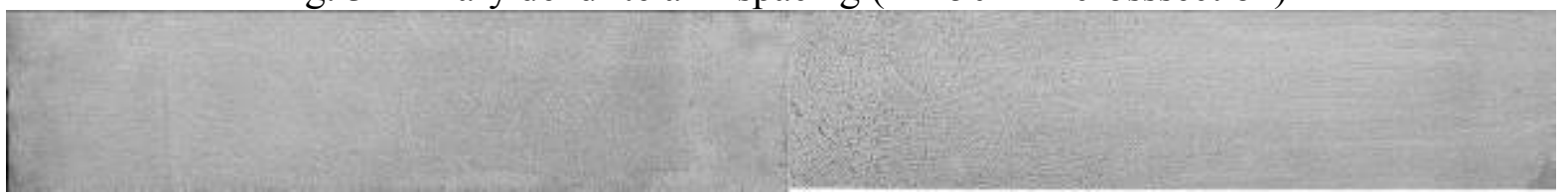

The middler part of the ingot

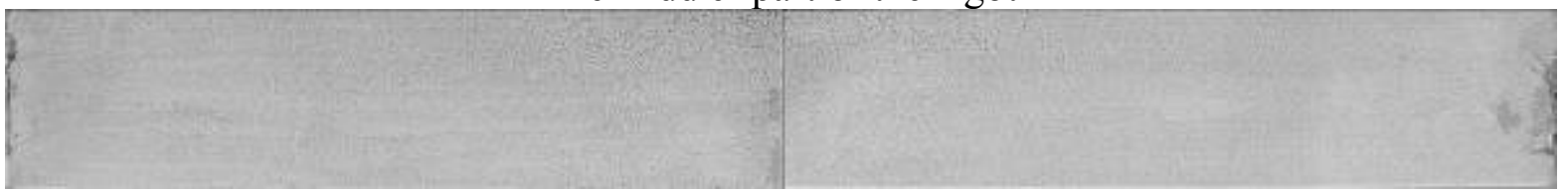

The bottom part of the ingot

Fig. 4 The microstructure of the water-cooled ingot

Porosity in the water-cooled ingot. One of the most important types of defects that can form in cast products is porosity. There are many types of porosity, but the most severe is microporosity. It has a strong negative effect on mechanical properties, especially on ductility and fatigue, because internal pores act as local stress concentrators and crack initiation sites [11]. The porosity in castings calculated by this simulation is show in Fig. 5. It can be seen that, though they are casting with different casting 
temperatures, but they have similar solidification microstructures. The different porosity types and positions are formed in the top part of the casting ingot. Their location is from top side $600 \mathrm{~mm}$ to 1600 $\mathrm{mm}$ and from side $500 \mathrm{~mm}$ to $1500 \mathrm{~mm}$. There are two main causes of microporosity: shrinkage porosity and gas porosity. The first one is on the top of the casting, as shown in Fig. 5 and Fig. 6. It is due to the volume change upon solidification combined with restricted feeding of liquid to the final solidification region. Fig. 6 shows two shrinkage porosities appear in the water-cooled ingot. The second one is formed for the condensation of dissolved gases in the melt upon freezing, as a result of the different in solubility of such gases in the liquid and solid phases.

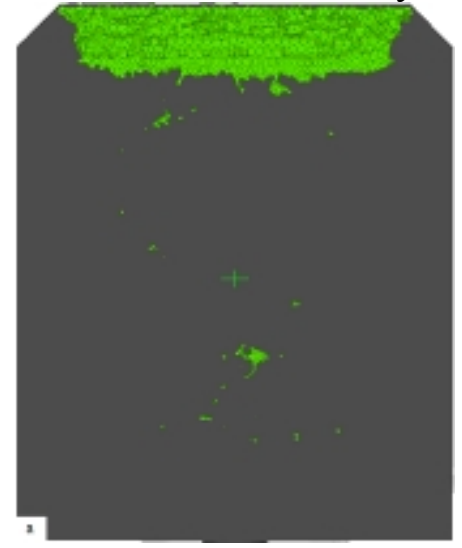

(a) Casting at $1530^{\circ} \mathrm{C}$

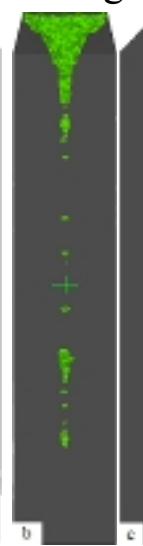

Fig. 5 X-ray perspective view of porosity

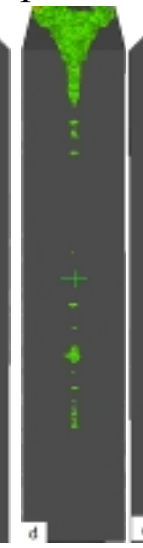

(b) Casting at $1540^{\circ} \mathrm{C}$

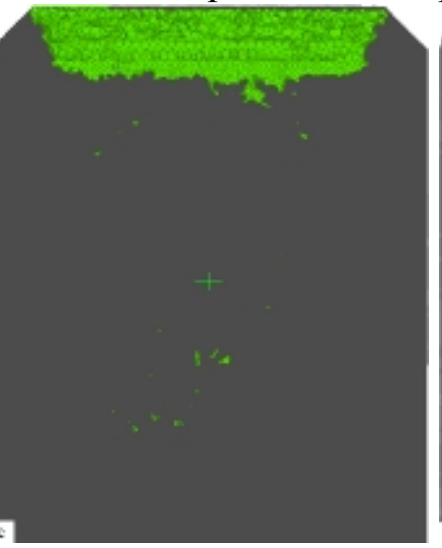

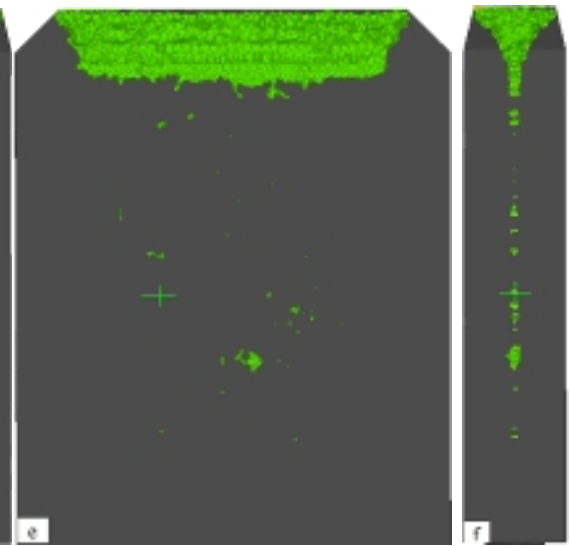

(c) Casting at $1550^{\circ} \mathrm{C}$

Table 1 shows the sodidification time and the deepth of the shrinkage porosity at different casting temperatures. The sodidification time is similiar, but with the increasing of the casting temperature, the deepth of the shrinkage porosity become bigger. Decrease the casting temperature from $1550^{\circ} \mathrm{C}$ to $1530^{\circ} \mathrm{C}$, the deepth of the shrinkage porosity will deduce $31 \mathrm{~mm}$.

Table 1 Shrinkage porosity depth at different casting temperature

\begin{tabular}{ccc}
\hline Casting temperature $/{ }^{\circ} \mathrm{C}$ & Finish solidification time $/ \mathrm{s}$ & Deepth of the shrinkage porosity $/ \mathrm{mm}$ \\
\hline 1530 & 4725 & 333 \\
1540 & 4745 & 348 \\
1550 & 4770 & 364 \\
\hline
\end{tabular}

\section{Summary}

(1) The temperature decrease very quickly and keep the similar curves for different nodes on the surface of the cast. But for the node 72282 on the corner of the mold, the temperature curve has a short time increasing between $1000 \mathrm{~s}$ and $2000 \mathrm{~s}$.

(2) With the increase of pouring temperature, the columnar grain area is bigger. when pouring temperature is $1530{ }^{\circ} \mathrm{C}$, ingot solidification organization mainly composed of fine crystal area and a wide range of internal equiaxed grains zone.

(3) The different porosity types and positions are formed in the top part of the casting ingot. Their location is from top side $600 \mathrm{~mm}$ to $1600 \mathrm{~mm}$ and from side $500 \mathrm{~mm}$ to $1500 \mathrm{~mm}$.

(4) Decrease the casting temperature from $1550^{\circ} \mathrm{C}$ to $1530^{\circ} \mathrm{C}$, the depth of the shrinkage porosity deduces $31 \mathrm{~mm}$.

\section{Acknowledgements}

The authors would like to thank PhD Research Startup Foundation of Liaoning Institute of Science and Technology[1406B06], Program for Liaoning Excellent Talents in University [No. LJQ2015056], National Natural Science Foundation of China [51574063] and National High Technology Research and Development Program 863 [2012AA03A503].

Correspondent author: Huishu ZHANG, E-mail: huishuzhang@163.com. 


\section{References}

[1] T Kitagawa, M Nakada, M komatsu, et al. Development of Undirectionally Solidified Large Scale Ingots for Heavy Gauge Plats. Transactions ISIJ, 1985, 25(1): 1227-1236.

[2] Zhu P P, Smith R W. Dynamic simulation of crystal growth by monte carlo method-I. model description and kinetics, Acta Metallurgica, 1992, 40(4): 683-692.

[3] Zhu P P, Smith R W. Dynamic simulation of crystal growth by monte carlo method-II. ingot microstructures, Acta Metallurgica, 1992, 40(12): 3369-3379.

[4] A A Galushka, Luk'yanova N A, Ol'shanskaya T V, et al. Low-waste Process of Large-size Plate Ingot ESR Production. Stal', 1993, 33-34.

[5] J P GU, C Beckermann. Simulation of Convection and Macrosegregation in a Large Steel Ingot. Metallurgical and Materials Transactions A, 1999, 30A(5): 1357-1366.

[6] E J Pickering. Macrosegregation in Steel Ingots: The Applicability of Modelling and Characterisation Techniques. ISIJ International, Vol. 53 (2013), No. 6, pp. 935-949.

[7] Z H Zhang, L Feng, F C Zhao. Numerical Simulation of Filling Process in Large Steel-Ingot. Applied Mechanics and Materials. 2013, 395-396: 1212-1217.

[8] K Marx, S Rödl, S Schramhauser, M Seemann. Optimization of the filling and solidification of large ingots. La Metallurgia Italiana - 2014, (11-12): 11-19.

[9] Z H Duan, X Du, H F Shen, B C Liu. Numerical study of macrosegregation in a large steel ingot with multiple pouring process. Materials Science and Engineering, 2015, 84, doi:10.1088/1757-899X. [10] J Guo, C Beckermann, K Carlson, D Hirvo, K Bell, T Moreland, J Gu, J Clews, S Scott1, G Couturier1 and D Backman. Microporosity Prediction and Validation for Ni-based Superalloy Castings. Materials Science and Engineering, 2015, 84, 012003 doi:10.1088/1757-899X/84/1/012003.

[11] J A Dantzig, M Rappaz. Solidification. Lausanne, Switzerland: EPFL Press, 2009, 479. 